Rev. Latinoam. Psicopat. Fund., São Paulo, v. 14, n. 2, p. 252-267, junho 2011

\title{
Clínica da toxicomania: uma expressão melancólica?*
}

\author{
Shana Nakoneczny Pimenta \\ Maria Virgínia Filomena Cremasco \\ Serge Lesourd
}

O presente artigo tem como objetivo compreender por meio da teoria psicanalítica um caso clínico, que se apresenta inicialmente como um caso de toxicomania. No entanto, na construção da transferência, percebeu-se uma profunda tristeza que nos remete à melancolia. A partir daí, traçamos paralelos teóricos entre a toxicomania e a melancolia, concluindo, a respeito do nosso caso, que a toxicomania e a melancolia bebem da mesma fonte metapsicológica.

Palavras-chave: Toxicomania, melancolia, psicanálise, clínica

* O presente artigo foi baseado na tese acadêmica do curso de Master Recherche II/ Modalidade: Psychopathologie et études psychanalytiques, realizada na Universidade Louis Pasteur, Strasbourg, França, intitulada De la toxicomanie à la mélancolie: considérations psychanalytiques sur un cas de toxicomanie, apresentada no ano de 2007, de autoria de Shana Nakoneczny Pimenta. 


\section{Introdução}

A clínica está e é, em si, a origem da psicanálise. Como poderia ser diferente, se ela é o fundamento da riqueza de sua construção teórica, bem como de sua dificuldade? É escutando a clínica, que poderemos, através do particular, ter acesso ao pathos coletivo.

Desta maneira, este estudo parte dos questionamentos e interrogações suscitados pela clínica de Marcos, ${ }^{1}$ um paciente que se apresenta, em um primeiro momento, como "dependente químico". À medida que a clínica avança, começa-se a perceber que, sob a máscara da toxicomania, repousa um sujeito que padece de uma tristeza e de uma posição subjetiva que consideramos como melancólica. Assim, a clínica, por ela mesma, obrigou-nos a questionar os laços eventuais existentes entre toxicomania e melancolia.

\section{Toxicomania...}

Marcos quer tratar de duas "doenças": a dependência química e a depressão. Ele diz que estas são duas doenças que "estão ligadas: quando uma aparece, a outra some". Marcos cheira cocaína há 14 anos, e esteve internado durante um mês em um hospital psiquiátrico para fazer uma desintoxicação, e logo após sua saída, procura atendimento psicológico individual.

1. Nome fictício de paciente atendido por uma das autoras, no já extinto Centro de Estudos das Toxicomanias "Dr. Claude Oliveinstein" na Universidade Federal do Paraná. O paciente assinou termo de consentimento para que os dados de seu tratamento fossem publicados. Seus dados pessoais foram alterados para que sua identidade fosse preservada. 
Marcos é casado e tem duas filhas. Ambas moram em outro Estado com sua ex-esposa, que não quer mais vê-lo. Sem dinheiro, sem emprego e em uma cidade desconhecida, Marcos é obrigado a morar com sua mãe, o que lhe coloca em uma posição extremamente angustiante, já que ele sente "muita raiva" dela. A razão desta raiva, diz ele, está na sua "má criação": criado só pela mãe desde os oito anos, quando seu pai é assassinado, Marcos se queixa de ter sido "mau criado", de nunca ter tido "carinho de mãe: ela é fria", diz o paciente. Parece que algo a mais faltou, pois como ele diz "ela parece mais uma amiga do que uma mãe".

Porém, curiosamente, não foi sempre assim. Até quatro anos, Marcos era "colado" à sua mãe. Ela não podia nem mesmo ir sozinha ao banheiro, que ele chorava desesperadamente. Ele conta que com esta idade viveu um "trauma" (sic) que marcou para sempre sua vida: sua família decide mudar para outra cidade, e o pai de Marcos, com a intenção de arrumar a casa para quando os filhos e a mulher chegassem, foi à frente e levou-o junto. Quando Marcos percebe que sua mãe tinha ficado para trás, sente muito medo e entra em um profundo desespero. O paciente relata, com uma imensidão surpreendente de detalhes, esses três dias de profundo desamparo, durante os quais chorou sem parar e que só tiveram fim com a chegada de sua mãe. Este evento marca, para Marcos, o começo de uma tragédia, o início de sua ruína.

A partir desse episódio, relatado como um trauma pelo paciente, Marcos vivencia cada afastamento de sua mãe como uma separação traumática que traz à tona sentimentos de abandono, de fragilidade, e de intenso desamparo.

Para ele, sua vida teria sido diferente se ele tivesse tido "carinho de mãe". "Na verdade, o que me faltou foi um amparo, uma proteção. E então, eu fui buscar tudo isto fora da minha casa, na rua, com o traficante." Abandonado, desamparado, Marcos busca nas ruas um amparo que possa substituir aquilo que sua mãe não pôde lhe dar. Marcos nos explicita então o quanto lhe faltou suporte, um algo a mais, um carinho de mãe, carinho este nunca encontrado. Com muita lucidez e um tanto de dor, ele nos revela a dimensão do seu desamparo, que ele tenta esquecer com o recurso da droga.

Seu discurso, a dor explícita na sua fala, sua fragilidade e a transferência que ele despertava, como se precisasse ser protegido e receber carinho. Estes foram alguns dos dados que nos permitiram a hipótese de um desabamento constitutivo que marca sua vida, e que está intimamente ligado ao seu sofrimento melancólico e ao uso abusivo de drogas.

Para tal, apoiamo-nos no conceito freudiano de Situation der Hilflosigkeit, (situação de desamparo), como descrita por Freud (1926/1992), a fim de buscar um esclarecimento para estes momentos de ruína, para esta falta de amparo, para este estado de abandono do qual Marcos padece. Explicamo-nos: o estado de de- 
samparo se produz quando o bebê, ainda prematuro psíquica e biologicamente, absolutamente dependente de sua mãe para sobreviver, encontra-se confrontado com a ausência materna. Desta forma, pode-se dizer que o estado de desamparo é definido pela perda de objeto de amor quando este último ainda não tinha sido simbolizado.

Se pudermos ampliar esse conceito considerando que não só os bebês, mas também as crianças e adultos podem estar sujeitos a este estado, poderemos compreender melhor certos momentos de intensa angústia e pânico vivenciados pelo nosso paciente. O conceito de Situation der Hilflosigkeit nos auxilia a iluminar certas passagens da clínica que ficaram antes turvas. Ele nos ajuda a esclarecer a intensa reação de Marcos diante dos abandonos maternos; bem como nos faz compreender o motivo pelo qual ele precisava estar colado à sua mãe: se Marcos não possuía ainda um significante materno, um traço, uma palavra, um cheiro, que pudesse representar sua mãe nos seus momentos de ausência, podemos facilmente imaginar o seu desespero quando ela se afasta, quando há uma separação.

O "primeiro trauma", segundo seu relato, acontece quando ele se separa de sua mãe, e Marços, privado de sua presença física, não acha um traço, uma marca, um significante nele inscrito que possa representá-la durante esta ausência. Sem traço, sem amparo, sem ajuda - hilflos. Esta situação de desamparo irá acompanhá-lo durante toda a sua vida, e é para lidar com ela que ele acha a solução mágica da cocaína.

Lacan (1958-1959) empresta o conceito de Situation der Hilflosigkeit freudiano e o amplia ao dizer que o estado de desamparo se dá no momento em que o sujeito se confronta com o desejo desconhecido e voraz do Outro (A), diante do qual o sujeito se vê sem recursos e sem socorro. Seria exatamente a situação do bebê diante do desejo indecifrável do outro materno, que lhe vem como incompreensível e excessivo. Este é o momento que deixa o sujeito no afeto de angústia: ao estar sem recursos diante deste desejo inominável do Outro, a angústia assalta o sujeito.

Hoje, quando Marcos está perto de sua mãe, precisa odiá-la, rejeitá-la; parece ser este o modo de se afastar da ameaça que ela representa. Para ele no lugar da resposta fálica à pergunta: O que é que ela quer? - um enigma é lançado. Esta incógnita abre a possibilidade de que ele todo seja o alvo materno, de que seu corpo corresponda à voracidade do desejo do Outro, e, portanto, vemos Marcos encenar, durante toda sua jornada, fugas, artifícios e artimanhas, para tentar colocar um empecilho na boca feroz deste jacaré.

Marcos encontra na cocaína a solução que parece perfeita para escapar da boca escancarada do Outro. A droga vem recriar alucinatoriamente um outro corpo, um corpo que não corresponde ao voraz desejo materno, um corpo de um 
"homem de verdade", nas palavras de nosso paciente. Fazendo recurso à Operação do Phármakon (Le Poulichet, 1987, p. 58). Marcos se sente enfim um "homem de verdade"; com todos os requisitos que, segundo ele, fazem um homem: ele é capaz de ter relações sexuais, é valente, "sai na porrada" ou pode até matar: ele não tem medo de nada. Torna-se "imbatível". No entanto, sem o recurso tóxico, Marcos volta a ser, como ele mesmo se descreve, aquele "homenzinho, com medo de tudo, encolhidinho num canto". Sem a droga, ele se sente ameaçado.

A relação de Marcos com o seu próprio corpo é algo que nos chama atenção. Não só pelo fato de que a droga lhe proporciona a ilusão de possuir um corpo de homem de verdade, mas também por todo o seu discurso, que é bastante corporalizado. Ele exprime seus sentimentos, seus desconfortos, seus medos com adjetivos que têm uma relação intensa com o corpo, com o orgânico: "impotente", "cansado", "fissurado" (sic.), "quebrado" (sic.), "impregnado" (sic.) etc. Da mesma forma, Marcos estava certo de que sua dependência à cocaína, sua depressão, bem como sua impotência sexual eram "doenças" orgânicas, sem causas psíquicas. Nos momentos nos quais retorna a cheirar, justifica dizendo que era seu corpo que precisava.

Logo percebemos que o corpo aparece em excesso no discurso de Marcos. Este excesso de corpo denuncia, na verdade, a insuficiência da imagem do corpo próprio: falta de uma palavra, de um suporte simbólico, de um olhar pleno de significantes que atravessasse e significasse o corpo do infans durante o estádio do espelho; o toxicômano padece de uma imagem mal-elaborada de seu corpo. Durante a formação da imagem do corpo próprio - momento dialético em que o infans se apropria da imagem do seu corpo refletida no espelho, e a reconhece como sendo sua - faltou um significante vindo do Outro, que desse um valor àquela imagem ou mesmo a unificasse. E se o significante não vem tecer a imagem, isto é, se a imagem não é "signifiantissée", ${ }^{2}$ o reflexo do corpo do infans no espelho continua a ser uma imagem gelada e, por conseguinte, a imagem do corpo próprio resulta faltante, vacilante. Em Marcos essa falta de um significante unificador de sua própria imagem parece ter deixado precocemente uma marca, um traço ainda não representado e, portanto, não memorizável. Posteriormente (aprèscoup), com o afastamento de sua mãe, esse traço é revivido e pode finalmente ser significado como abandono. Esse é o momento de uma grande angústia, pois o abandono ressignifica todas as vivências anteriores e posteriores de sua vida.

2. Neologismo que brinca com as palavras francesas signifiant (significante) e tisser (tecer): signifiantissé quer dizer, então, tecido pelo significante. 
Em vista disso, a sua tentativa parece ser justamente a de estabilizar a imagem vacilante do corpo próprio com o recurso tóxico. Marcos, por sua vez, ao tentar remediar ou desmentir o desmoronamento da sua imagem, busca na droga um remédio, tentativa desesperada e paradoxal de conservação de uma imagem sólida do corpo próprio. A cocaína funciona, desta forma, como um remédio, um objeto de autoconservação que recria um corpo alucinatório não despedaçado e estável, dando finalmente a Marcos a ilusão de um corpo de "homem de verdade".

Esta falha na formação da imagem do corpo próprio está intimamente ligada com a situação de desamparo. Segundo Costa Pereira (1999), a situação de desamparo é um momento existencial que está em relação direta com a desintegração da imagem do corpo próprio. Entendemos - a partir daí - que cada vez que o sujeito se encontra em uma situação que o remete à situação de desamparo, atualizada a cada encontro com a falta, o fantasma do corpo despedaçado o assombra.

A clínica explicita a dificuldade que o toxicômano enfrenta ao encarar a falta: ele se desespera, pois não aprendeu a representá-la simbolicamente. A falta, para ele é toda, é Um, é devoradora. Marcos usava todos os recursos que estavam ao seu alcance para fugir da falta, e certamente a cocaína era um dos seus instrumentos mais importantes, porém não o único. Percebemos que ele se vincula aos objetos de modo a não deixar espaço para que a falta apareça: tal qual quando ele se agarrava às pernas de sua mãe para impedi-la de ir sozinha ao banheiro, Marcos se agarra com uma força desesperada aos seus objetos de amor; até chegar ao ponto de se tornar dependente destes objetos. Desta maneira, ele passa de um objeto de dependência a outro, num movimento metonímico que lembra o deslizamento de uma cadeia significante: mãe, ex-mulher, cocaína, bebida, a psicóloga...

Esta maneira intensa de se relacionar com seus objetos de amor revela uma tentativa de não deixar espaço possível à falta, à perda, ao buraco do desejo. Assim, nota-se que Marcos transforma seu desejo em necessidade, o amor em dependência. Dito de outro modo, ele opera um tratamento particular do desejo e o transforma em pura e biológica necessidade. Em outros termos, o toxicômano é aquele que busca objetos na realidade a fim de colmatar o hiato de seu desejo; isto é, ele tenta preencher com objetos reais a falta intrínseca ao desejo com a intenção de acabar com a insatisfação. A droga aparece então como a solução perfeita, já que é um objeto consumível, comprável, sempre disponível, proporcionando-lhe uma sensação temporária de satisfação alucinatoriamente plena.

Ora, podemos dizer então que o toxicômano é aquele que segue, cegamente e sem saber, a lógica pós-moderna do bom consumidor. Pois ele crê na promessa do consumismo de que há um produto disponível no mercado - mercado negro, mas mesmo assim submetido às regras do mercado capitalista - que lhe 
oferece a satisfação plena. O toxicômano tem fé nos milagres pregados pelos produtos oferecidos, e por isso ele os utiliza e goza com eles sem nenhum pudor. $\mathrm{O}$ toxicômano encarna, inegavelmente, o papel do consumidor exemplar.

Assim sendo, ele transforma a falta-a-ser (manque-à-être) em vazio possível de se preencher, em uma lacuna na qual todos os objetos são bem-vindos. O toxicômano desfigura a falta do desejo - fenda simbólica - em falta orgânica, fenda possível de ser fechada. Desta forma, não podemos ignorar que o sentimento e a sensação de falta provocados pela ausência da droga - a chamada "fissura" (sic) - têm um efeito específico e particular na psicodinâmica do sujeito: a falta-a-ser é camuflada pela falta física da droga, pela "fissura" (sic), que é uma falta possível a ser preenchida.

\section{Melancolia...}

No decorrer dos atendimentos percebemos que o aparato conceitual teórico da toxicomania se mostrou insuficiente para compreender profundamente nosso caso clínico, pois, apesar da queixa principal de Marcos ser a sua "dependência química", evidenciou-se que a droga ocupava uma posição de camuflagem contra o que o assombrava.

É seguindo suas pistas, suas palavras e nossa transferência que desembocaremos no campo do sofrer melancólico. Refletindo sobre a psicodinâmica desse paciente fica-nos claro que a cocaína não era a causa de seu sofrer, mas servia, podemos dizer, de instrumento, de um remédio como suporte para o desamparo que marca a sua constituição patho-lógica.

Além do mais, a relação entre toxicomania e o que ele chama de depressão também é apontada pelo paciente: segundo ele, estas são "doenças interligadas, quando uma aparece, a outra some." Importante sublinharmos como Marcos vivenciava esses períodos de depressão: um colapso narcísico, como frequentemente vemos nos processos melancólicos, ou seja, um completo esvaziamento de si; não há ação, apenas uma profunda culpabilidade mortífera. A depressão profunda que ele vivencia metaforicamente é a criança morta da melancolia.

Perguntamo-nos então qual seria a relação entre essas duas formas de sofrimento psíquico? Como se dá essa relação de interdependência?

Freud (1917) havia aproximado a toxicomania da melancolia agrupando-as sob o mesmo termo de psiconeurose narcísica. Freud (1917, p. 270) sublinha que um "mecanismo significativo" para as "afecções narcísicas" é o da "incorporação canibalística" do objeto de amor, que presume uma escolha de objeto dada sobre uma base narcisista. A incorporação canibalística é uma reação, típica da 
infância, à perda do objeto de amor. Isto é, se o objeto de amor desaparece quando sua representação psíquica ainda não foi possível, o sujeito, a fim de se defender do sentimento de desamparo que vem junto com esta ausência, devora o objeto de amor e não seu representante, já que este não foi ainda criado. Desta forma, pode-se dizer que este tipo de incorporação canibalística do objeto é uma defesa à situação de desamparo.

Partindo do princípio que o toxicômano é um sujeito que padece de uma psiconeurose narcísica, podemos observar a olho nu o mecanismo da incorporação canibalística. $\mathrm{O}$ ato de consumir um produto é uma maneira óbvia e primitiva de incorporar o objeto em si mesmo. Da mesma forma fixar-se em objetos de amor tornando-se assim dependentes deles, tal como Marcos o faz, é também uma forma de incorporação canibalística. Na verdade, o que o toxicômano quer afastar, quando engole seus objetos de amor, é a falta, a distância, a ausência; pois esses significantes o remetem diretamente ao estado de desamparo e à ameaça de desmantelamento do corpo próprio. Assim, essa reação canibalística teria a função de promover uma restauração narcísica, ao nível da falta originária da imagem especular e da identificação primária.

Como funciona este mecanismo de incorporação canibalística na melancolia? A definição freudiana do complexo melancólico se baseia em três pressupostos que são: a perda do objeto, a ambivalência, e a regressão da libido no ego (moi). O mecanismo de incorporação canibalística possui uma intensa ligação com estes três pressupostos. O sujeito que sofreu a perda de um ente ou um objeto querido incorpora, sob o modo do canibalismo de identificação ao objeto, o objeto perdido em si na tentativa de anular esta perda. Dizendo de outro modo, uma parte do ego (moi) do sujeito em luto se identifica com o objeto perdido. Esta identificação, operada sob a forma da incorporação canibalística, vai provocar a regressão da libido no ego, pois agora o sujeito-dor passa a investir toda a sua libido nesta parte egoica identificada ao objeto perdido. Consequência também deste processo, é a ambivalência, outro pressuposto da melancolia, pois ao mesmo tempo em que o ego manifesta sentimentos de amor ao objeto perdido, muita raiva e ódio são também dirigidos a ele, já que ele foi o causador de tanta dor (Freud, 1917, p. 264).

Para Fédida (1978) a ambivalência do canibalismo se esclarece se dissermos, correlativamente, que a angústia melancólica é canibalística e que ela diz respeito, a esse título, à dependência do eu à ameaça da perda de seu objeto: essa ambivalência significa que o meio mais certo de se preservar da perda do objeto é destrui-lo para mantê-lo vivo. A incorporação canibalística não seria então o ato simbólico de uma resolução da perda. Ela é a satisfação imaginária da angústia de se nutrir do objeto perdido - objeto cuja perda foi, de qualquer maneira, necessária para que ele permanecesse vivo e presente em sua realidade primitiva alucinadamente conservada. 
O canibalismo seria então a expressão mítica de um luto melancólico, tipo assassinato, de um objeto sob a sedução do qual o eu se encontrou submetido e do qual ele não pode resolver se separar, assim que testemunha a angústia de mantê-lo presente em sua ausência.

Desta maneira, a partir da análise do conceito de incorporação canibalística, podemos apontar um primeiro ponto de convergência metapsicológica entre a melancolia e a toxicomania: elas partilham do mesmo mecanismo de incorporação de objeto, a fim de evitar a perda do mesmo. Ou seja, para manter uma identidade ilusória do "mesmo", ele porta a vocação imaginária de jamais perder o "outro", esse o qual apenas a destruição por devoração pode assegurar que ele não poderá jamais abandonar.

Este dispositivo revela também uma importante falha no que concerne à introjeção da representação do objeto de amor: falta um significante, uma representação introjetada do objeto. O melancólico, assim como o toxicômano, devora o objeto para destruir sua alteridade e mantê-lo incorporado como mesmo e único recurso disponível para preservá-lo, afastando a ameaça de destruição proveniente da situação de desamparo.

Ora, a incorporação canibalística do objeto é um mecanismo de defesa próprio às afecções narcísicas. Este mecanismo demonstra uma tentativa de restauração narcísica, já que o sujeito investe a libido em si mesmo. A partir deste elemento, podemos falar de uma conservação narcísica, isto é, de um recuo narcísico que consiste em salvaguardar a libido em si. No contexto melancólico, o sujeito investe a libido no objeto perdido incorporado ao eu. Já no caso da toxicomania, o sujeito investe no seu próprio corpo idealizado: utilizando a substância tóxica, restaura alucinatoriamente uma imagem inteira e íntegra de si.

Se compreendermos a toxicomania pelo modelo melancólico da introjeção canibalística do objeto perdido, não poderíamos então pressupor que o objeto perdido do toxicômano seria a imagem do corpo próprio? Ou seja, poderíamos considerar o toxicômano como um melancólico que sofreu a perda de um objeto, mas este objeto corresponderia, neste caso, à imagem unificada do seu corpo no espelho? Ora, é sabido que o melancólico é aquele que perdeu um objeto, mas que, contrariamente ao enlutado, ele não sabe o que perdeu; a perda é inconsciente, ela seria mais "idealizada". Não poderíamos então pensar que, na toxicomania, esta "perda inconsciente" seria, sobretudo, uma falha na constituição de uma imagem "ideal" do corpo próprio?

Se supusermos que este toxicômano é um melancólico que investiu na imagem ideal de um corpo próprio não constituído, perguntamo-nos imediatamente: como foi a formação da imagem corporal especular para ele?

A teoria psicanalítica nos diz que o sujeito melancólico também carrega na sua constituição psíquica uma falha em relação à sua imagem. Uma das "condi- 
ções necessárias" para a "emergência" do complexo melancólico, segundo Lambotte (2003), seria uma falha na erogenização da imagem do infans no momento pré-especular.

(...) nossa primeira hipótese relativa à origem da melancolia: a ausência ou uma fragilidade especular grande demais, devido à insuficiência primária de uma imago materna. (...) a fase especular apresentaria as condições necessárias à emergência da melancolia, pois a função insuficiente do olhar materno, ao invés de contornar a silhueta na criança com um prazer de troca, atravessou o corpo da criança como se ele estivesse dirigido a um outro lugar ou como se ele se perdesse ao longe sem limite. (p. 208)

Isto é, devido à ausência de um olhar do Outro pleno de desejo, o sujeito melancólico erra na identificação ao vazio, ao nada: nada que reflete o que ele viu nos olhos da sua mãe enquanto ela (não) o olhava. Pois, este olhar que atravessou, sem ver, o corpo do melancólico, estava dirigido às figuras de um ideal tão exigente que a mãe não reconheceu no corpo de seu filho. Deste modo, sublinhemos aqui mais uma convergência metapsicológica com a toxicomania: tanto o melancólico quanto o toxicômano sofrem de uma imagem especular vacilante, consequência de uma falha ou de uma falta do Outro materno durante a dialética do espelho.

A fim de remediar este desastre no espelho, a criança vai buscar desesperadamente a imagem ideal sob a qual o olhar materno está inclinado. O melancólico se estrutura sob um modelo de um ideal de Eu perfeito e longínquo, com o qual ele se compara e sai sempre derrotado, pois este ideal não é possível de ser atingido.

Podemos assim compreender melhor as autoacusações e autoinjúrias que o melancólico se faz, já que ele não pode atingir este ideal de perfeição que lhe é imposto e que ele incorpora como se fosse o seu. Desde sempre o melancólico se sente desacreditado e desacredita, ele mesmo, no mundo ao seu redor, bem como em todo laço que lhe permitiria constituir seu ser-no-mundo. Marcos, vítima de um olhar materno que não o olhou verdadeiramente, perde-se numa identificação ao nada, ao vazio visto nos olhos de sua mãe - a criança morta da melancolia.

Sendo assim, não poderíamos pensar que ele erige a droga como um objeto ideal a ser incorporado na tentativa de se refazer alucinatoriamente, mas agora não mais com um corpo translúcido, e sim com um corpo cuja densidade é atestada pela Operação do Phármakon que o transforma em um "homem de verdade".

Ficou-nos cada vez mais evidente que a toxicomania de Marcos se tratava, sobretudo, de uma tentativa desesperada de cura, de uma rolha para tentar tam- 
ponar um abismo profundo. Isto é, a toxicomania se apresenta neste caso como a expressão clínica da melancolia, de forma que, quando Marcos decide parar de usar drogas e fica longos períodos em abstinência, seu sofrimento melancólico emerge com toda a força por intermédio do que ele vivencia como uma profunda depressão. Assim sendo a cocaína funcionava como um antidepressivo, uma tentativa de fazer calar o sofrimento melancólico.

Além disso, os dados sobre sua infância, a relação que ele tinha com sua mãe, com seu meio social e com seu próprio corpo, deixaram-nos entrever seu sofrimento como uma dificuldade de viver no mundo, o que nos remete diretamente ao sofrimento melancólico. Para ele, viver era inacreditavelmente difícil: ele não conseguia fazer as coisas básicas do dia a dia, como escovar os dentes, cozinhar, pegar ônibus, tudo isto exigia de Marcos um esforço sobre-humano: "Como é que alguém pode ser feliz neste mundo, sem usar drogas?".

O incompreensível para Marcos é como ser feliz com esses pequenos e banais gozos fálicos do cotidiano. Para ele, a felicidade estava naqueles curtos, porém intensos momentos de completude, em um outro corpo, em um outro mundo, um mundo e um corpo alucinatórios mais completos: num mundo onde o gozo é completo, onde o gozo é o gozo do Outro, onde o gozo é o Gozo. Parece que quando Marcos não encontra esta forma de Gozo, a única saída que ele conhece é se afundar na areia movediça do sofrimento melancólico que não nos parece menos impregnado de gozo do que aquele do "barato" (sic) da droga. Marcos alterna duas posições: ou ele está identificado ao vazio melancólico, ou ele está preso ao Gozo adictivo. Dito de outro modo, quando ele não suporta mais o abismo melancólico, procura um alívio alucinatório, e para tal, dará seu corpo como garantia para este gozo destrutivo. Lambotte (2002) nos dá a pista:

(...) para um sujeito melancólico identificado ao vazio deixado pelo outro desaparecido, ao vazio do outro original que poderia ser "tudo", se trata de se defender de aspirar um gozo ainda mais próximo, insuficientemente distante, e que abre a via para a adicção. Considerar a melancolia como um tipo de adicção poderia oferecer matéria a comparações frutuosas no plano da construção metapsicológica; em relação ao negativismo generalizado como indício do gozo e a realidade cotidiana como limite, que constituiriam as marcas principais de tal conduta. (p. 30; tradução livre)

Seguindo então nosso trabalho de comparação metapsicológica - que esperamos, como nos indica Lambotte, ser frutuoso - podemos concluir, a partir da citação acima, que o melancólico, assim como o toxicômano estão presos a um gozo aniquilante. No entanto, o fenômeno, ou seja, o comportamento que testemunharia a captura em tal gozo se exprime diferentemente na melancolia e na toxicomania: na primeira, o sujeito gozaria com o seu negativismo, característica típica do quadro melancólico, enquanto que na segunda, ele goza com a droga. 
Aliás, não poderíamos pensar que o gozo do toxicômano é também composto de uma boa dose de negativismo, no sentido de uma autonegatividade, do fato que ele se serve da autodestruição de seu corpo, carapaça de carne, para então liberar sua alma num vôo alucinado? O toxicômano, ao atuar o aniquilamento de seu próprio corpo como um efeito - colateral ou principal? - do uso de drogas em busca do gozo perdido, está na realidade inscrito numa lógica de negatividade. A droga seria então, no quadro toxicomaníaco, correspondente ao objeto de automutilação melancólica, o chicote que machuca o corpo para consumir a culpa. Como vimos, a operação canibalística da melancolia destrói para assegurar a existência, ou seja, a destruição atesta que algo existia. O consumo desenfreado, maníaco, de cocaína, por Marcos, levava seu corpo ao limite da destruição, atestando assim de alguma forma, que ele o possuía.

Citamos, a propósito, Escande (2002):

(...) se o melancólico é aquele que, vítima de uma ausência enigmática, se diz culpado, o toxicômano, colocando em causa a droga, encontra um objeto para erigir na realidade, não somente para afirmar a culpa, mas provavelmente para se livrar dela por (...) uma conduta de autodestruição ou pela tristeza depressiva que podemos entender aqui como uma pena, um castigo e sofrimento. (p. 141; tradução livre)

O que nós devemos finalmente realçar é que o melancólico, assim como o toxicômano apresentam, ambos, relação semelhante com o gozo. Tal qual o toxicômano, o melancólico procura, ele também, um gozo fora do simbólico que não passe pelo filtro das palavras, isto é, um gozo não fálico.

Desta forma, Marcos inscreve seu gozo fora da lei e da linguagem, seja pela via da droga ou pela via da melancolia. Ele alterna as duas posições, as duas formas de gozar este Gozo-do-Ser (Escande, 2002), mas de fato, vemos que se trata da mesma dinâmica, ou seja, ele não é capaz de renunciar à suposta completude desta posição. A sua relação ao Gozo-do-Ser coloca em evidência seu pavor do desejo e da falta.

Percebemos assim que há um mesmo contorno metapsicológico que confere uma silhueta semelhante à melancolia e à toxicomania. A instabilidade de imagem especular, o recurso à incorporação de tipo narcísica, um ideal de eu excessivamente poderoso, a autodestruição, assim como o isolamento dos laços sociais, são, até este momento, os elementos em comum, presentes na comparação destas duas situações clínicas. Além disso, o interessante aqui é destacar uma última, mas importante, coincidência metapsicológica entre esta duas maneiras de sofrer: tanto o toxicômano quanto o melancólico se protegem da falta intrínseca do desejo se escondendo atrás do escudo do gozo completo, Gozo-do-Ser. 


\section{Reflexões finais}

Após analisar nosso caso clínico e realizar esta incursão teórica pela toxicomania e pela melancolia, percebemos que, apesar da semelhança teórica entre estas duas formas de sofrimento, não podemos ignorar que certos fenômenos se apresentam diferentemente, isto é, que a Melancolia e a Toxicomania se manifestam fenomenologicamente de modo desigual. Contudo, as semelhanças e coincidências que encontramos no que diz respeito à construção metapsicológica e à sintomatologia são inegáveis.

A clínica de Marcos não nos deu motivos suficientes para separar a melancolia da toxicomania em duas organizações psicopatológicas diferentes, mas como dissemos, em duas posições diferentes. Propomos, sempre baseados na nossa clínica, que a melancolia e a toxicomania bebem da mesma fonte metapsicológica. Isto é, a toxicomania, neste caso, pode ser compreendida como uma expressão do vazio melancólico, que apresenta fenomenologicamente duas faces: uma maníaca, quando recorre às drogas, e outra profundamente depressiva, sem elas. Assim, podemos concluir, no que concerne ao caso clínico aqui trabalhado, que a toxicomania é uma manifestação de uma melancolia: Marcos esconde-se, ele mesmo, do seu sofrer melancólico, sob as plumas e brilhos da toxicomania.

A este respeito, Escande (2002) utiliza uma bela fórmula que diz que as adicções tóxicas seriam uma metamorfose atual da melancolia "fazendo da droga o substituto de uma ausência enigmática e o logro de um objeto perdido que nunca foi possuído, mas que, incluso no Eu [moi], impede a sua destruição" (p. 91; tradução livre). Desta maneira, o toxicômano erige a droga como objeto ideal e tenta, fazendo recurso ao tóxico, exorcizar o fantasma do vazio melancólico.

O melancólico que recorre à Operação do Phármakon ergue a droga como seu objeto ideal, objeto que é ao mesmo tempo seu salvamento e sua destruição - salvamento, pois evita um desabamento do eu, pelas suas propriedades alucinatórias e seu caráter narcísico; e destruição, pois a droga encarna o chicote do superego, que destrói o corpo como castigo e reencontra, neste mesmo ato, um gozo mortal.

Desta forma, escutando o caso clínico de um paciente que se apresenta, em um primeiro momento, como toxicômano, e deslocando nossa visão do fenômeno para olhar sob o quadro aparente, acabamos por concluir que sua toxicomania não era mais que uma forma de lidar com o abismo melancólico que o assombrava. 


\section{Referências}

Costa Pereira, M.E. Pânico e desamparo: um estudo psicanalítico. São Paulo: Escuta, 1999.

Escande, C. Passions de drogues. Les figures du ravage. Ramonville-Saint-Agne: Érès, 2002.

FÉDIDA, P. L'absence. Paris: Gallimard, 1978.

FreUd, S. Deuil et mélancolie. In: Euvres Complètes. Paris: PUF, 1988. V. XIII.

$\overline{\mathrm{VXX}}$. Inhibition, symptôme et angoisse. In: Euvres Completes. Paris: PUF, 1992.

LACAN, J. Le stade du miroir comme formateur de la fonction du Je telle qu'elle nous est révélée dans l'expérience psychanalytique. In: Ècrits. Paris: Le Seuil, 1966.

. (1958-1959). O seminário. Livro 6. O desejo e sua interpretação. Inédito.

Lамвотте, M.C. Le discours mélancolique. De la phénoménologie a la métapsychologie. Paris: Anthropos, 2003.

. La visée esthétique dans la mélancolie; la construction du contexte. In: $L a$ traversée de la mélancolie. Paris: Séguier, 2002.

Le Poulichet, S. Toxicomanies et psychanalyse: les narcoses du désir. Paris: PUF, 1987.

\section{Resumos}

(Drug addiction: an expression of melancholia?)

The present article uses psychoanalytic theory to discuss a clinical case that had initially been seen as a question of drug addiction. But during the process of constructing transference, a deep sadness related to melancholia became evident. Theoretical parallels were thus drawn between drug addiction and melancholia, which, in this case, led to the conclusion that drug addiction and melancholia derive from the same metapsychological source.

Key words: Drug addiction, melancholia, psychoanalysis, clinic

(Clinique de la toxicomanie: une expression mélancolique?)

Cet article vise à comprendre un cas clinique qui se présente d'abord comme un cas de toxicomanie sous l'angle de la psychanalyse. Au cours de la construction du transfert, on aperçoit une profonde tristesse qui nous remet à la souffrance 
mélancolique. Ceci nous mène à tracer des parallèles théoriques entre la toxicomanie et la mélancolie, d'où nous concluons, par rapport à notre patient, que ces deux psychopathologies puisent de la même source métapsychologique.

Mots clés: Toxicomanie, mélancolie, psychanalyse, clinique

(¿La clínica de la toxicomanía: una expresión melancólica?)

El presente artículo tiene como objetivo comprender por medio de la teoría psicoanalítica un caso clínico que se presentó inicialmente como un caso de toxicomanía. Sin embargo, en el proceso construcción de la transferencia fue posible reconocer una profunda tristeza, que reenvió a la melancolía. A partir de ese punto, esbozamos paralelos teóricos entre la toxicomanía y la melancolía, llevándonos a concluir, que en ese caso, tanto la toxicomanía como la melancolía se originan de la misma fuente metapsicológica.

Palabras clave: Melancolía, toxicomanía, psicoanálisis, clínica

Citação/Citation: Pimenta, S.N.; Cremasco, M.V.F.; Lesourd, S. Clínica da toxicomania: uma expressão melancólica?. Revista Latinoamericana de Psicopatologia Fundamental, São Paulo, v. 14 , n. 2, p. 252-267, jun.2011.

Editor do artigo/Editor: Prof. Dr. Manoel Tosta Berlinck

Recebido/Received: 28.1.2010 / 1.28.2010 Aceito/Accepted: 16.4.2010 / 4.16.2010

Copyright: @ 2009 Associação Universitária de Pesquisa em Psicopatologia Fundamental/ University Association for Research in Fundamental Psychopathology. Este é um artigo de livre acesso, que permite uso irrestrito, distribuição e reprodução em qualquer meio, desde que o autor e a fonte sejam citados/This is an open-access article, which permits unrestricted use, distribution, and reproduction in any medium, provided the original author and source are credited.

Financiamento/Funding: Os autores declaram não ter sido financiados ou apoiados/The authors have no support or funding to report.

Conflito de interesses/Conflict of interest: Os autores declaram que não há conflito de interesses/The authors declare that has no conflict of interest. 


\section{ARTIGOS}

\section{Shana Nakoneczny Pimenta}

Psicóloga; Título de Master Recherche em Psicopatologia e Estudos Psicanalíticos pela Université Louis Pasteur (Estrasburgo, França); Graduada pela Universidade Federal do Paraná (Curitiba, PR, Brasil)

Rua Capitão Souza Franco, 945/22

80730-420 Curitiba, PR, Brasil

e-mail: shana_pimenta@yahoo.com.br

\section{Maria Virgínia Filomena Cremasco}

Professora do Departamento de Psicologia da Universidade Federal do Paraná (Curitiba, PR, Brasil); Doutora em Saúde Mental pela Universidade Estadual de Campinas -Unicamp (Campinas, SP, Brasil); Pós-doutorado no Centre d'Études en Psychopathologie et Psychanalyse da Université Paris VII (Paris, França); Membro da Associação Universitária de Pesquisa em Psicopatologia Fundamental (São Paulo, SP, Brasil).

Praça Santos Andrade, 50/211 - Centro

80060-240 Curitiba, PR, Brasil

e-mail: virginiacremasco@ufpr.br

\section{Serge Lesourd}

Professor de Psicopatologia clínica e Diretor do doutorado de Ciências do Homem e das Sociedades da Universidade de Estrasburgo, Faculdade de Psicologia (Estrasburgo, França).

12 Rue Goethe

67000 Strasbourg, France

e-mail: serge.lesourd@unistra.fr 